\title{
Evaluation of antibacterial and in vitro antidiabetic activities of Phyllanthus amarus Linn. (phyllanthaceae) leaf ethanol extract
}

\begin{abstract}
Background information: Bacterial infection is largely responsible for a lot of anomalies in human health globally leading to many deaths in some cases especially in low income country. On the other hand diabetes caused by too much sugar in the blood still remain a problem in Africa resulting into partial paralysis or stroke as this often triggers blood pressures. Objective: This present study was carried out in order to evaluate antibacterial and in vitro anti diabetic activities of Phyllanthus amarus to justify the it's use in traditional medicine as antibacterial and antidiabetic agents. Methods: Antibacterial and in vitro antidiabetic activities of Phyllanthus amarus leaf aqueous extract. Antibacterial activity was evaluated on bacterial strains such as Staphylococcus aureus ATCC29213, Pseudomonas aeruginosa ATCC87391, Campylobacter jejuni ATCC13315, Streptococcus pyogenes ATCC8668, Bacillus subtilis ATCC12432, Salmonella typhi ATCC23564, Klebsiella pneumonia (clinical isolate) and VRE ATCC 6123. Antibacterial activity was carried out by agar well diffusion while susceptibility test was performed by Kirby Bauer's et al. method. The leaf extract was further subjected to inhibitory effect of glucose utilization by yeast cell evaluated by spectrophotometer using ascorbic acid as a reference drug. Results: Most of the microbes showed significant diameter zones of inhibition against the extract at various concentrations. The MIC and MBC further confirmed the potency of the aqueous extract on selected bacteria. In vitro antidiabetic evaluation of leaf extract showed a concentration dependent activity. Conclusions: The study therefore showed that the aqueous leaf extract of P. amarus possess significant antibacterial and inhibitory effect on glucose diffusion in vitro thus affirming the traditional claim of the use of plant in treating bacterial infection and diabetes.
\end{abstract}

Keywords: antibacterial, antidiabetic, phyllanthus amarus, mi c, mbc, bacterial strains
Volume 6 Issue 4 - 2018

\author{
Cletus A Ukwubile,' Jude A Odugu² \\ 'Medicinal Plants Research Laboratory, Central Academic \\ Center/Sancta Maria Clinic Integrated Laboratory Bali, Nigeria. \\ ${ }^{2}$ Department of Medical Microbiology, Ahmadu Bello University \\ Teaching Hospital, Nigeria
}

Correspondence: Cletus A Ukwubile, Medicinal Plants Research Laboratory, Central Academic Center Sancta Maria Clinic Integrated Laboratory Bali, Nigeria, Email doccletus@yahoo.com

Received: April 30, 2018 | Published: August 01, 2018

\section{Introduction}

Antibacterial are class of antimicrobial. An antimicrobial agent is define as a chemical substance that kills or inhibit the growth of microorganism such as bacterial, virus, fungi, algae, germs, protozoans etc, it may be a synthetic chemical or a natural product. An antibacterial is define as a chemical substance that kills or inhibit the growth of bacteria. They are classified into bacteriostatic and bactericidal. A bactericidal agent is one that kills bacteria concentration while bacteriostatic agent is one that inhibits the growth and development of bacterial. ${ }^{1}$ Antimicrobial agent possess diverse chemical structure and differs in their range of action. Some act on both Gram positive and Gram negative bacteria and they are said to have a broad spectrum of action, while some are only potent on either Gram positive and Gram negative bacteria are said to be narrow, examples of narrow spectrum antibiotics. ${ }^{2}$ Antibacterial are definitely effective in killing bacteria, however, there is considerable controversy surrounding their health benefits such as toxicity to some organs or harmful to some normal body floras. The non-residue producing agents have been used for many years and continue to be effective agents for controlling disease organisms in a wide variety of healthcare and domestic settings. When used under strict guidelines of application, the residue-producing agents have proven effective at controlling bacterial and fungal infection in clinical settings such as hospitals, nursing homes, neonatal nurseries and other health care facilities where there may be a high risk of infection. ${ }^{2}$ Because of the resistance developed by bacteria to most antibiotics nowadays, plantderived antibacterial agents are more preferable in the treatment of bacterial infection, with minimal side effects. ${ }^{2}$ Diabetes mellitus is a disease caused by inherited and or acquired deficiency in production of insulin by the pancreas or by the ineffectiveness of the insulin. ${ }^{3}$ This insulin deficiency results in increased concentration of glucose in the blood increase in blood increase in the blood glucose damages many of the body's systems in particularly, the blood vessels and nerves. The hyperglycaemia caused due to a decreased insulin production is called Type I diabetes and hyperglycaemia due to insufficient insulin production utilization is called Type II diabetes. ${ }^{3}$ And of these two, type- II diabetes is a major problem of today and it account for nearly $95 \%$ of total diabetic population of about 246 million. ${ }^{4}$ Since ancient times, plants have been exemplary source of Ayurvedic medicine and other literatures mention the use of plants in treatment of various human ailments. Country like India has 45,000 plants species and among them, several thousands have been claimed to posses medicinal properties. ${ }^{4}$ The commonly practiced treatment of diabetes includes oral anti-diabetic drugs, insulin injection and management through diet and physical exercise. A part from currently available therapeutic for the treatment of diabetes, traditional plants medicines are mostly used throughout the world for treatment of diabetes. ${ }^{5}$ 
According to the World Health Organization (WHO), the global prevalence of diabetes is estimated to increase from $6 \%$ in 2005 to $14.2 \%$ by the year 2025 majorly in the developing countries ${ }^{[6]}$. The middle east countries such as Pakistan, India, and Indonesia presently have the highest number of diabetic patients in the world and have been infamously known as diabetic capitals of the world. ${ }^{6}$ Resistance of type-II diabetes to synthetic drugs due occurs, and these drugs fail to significantly alter the course of diabetic complications and have limited use because of undesirable side effect and high rate of secondary failure. ${ }^{7}$ Phyllanthus amarus is a small herb common to central and eastern Nigeria as well as in India. It can grow to 30-60 cm in height and bloom with yellow flowers. All parts of the plants are used in Ayurvedic medicines because of their medicinal properties. Leaves of the plant are reported to contain lignin, alkaloids, flavonoids and glycosides. ${ }^{8}$ Studies on the extract of Phyllanthus amarus have shown that it also possess anti-hepatitis B activity, hepatoprotective, anticancerous, anti-microbial, and kidney stones dissolution properties. ${ }^{9}$

\section{Materials and methods}

\section{Materials}

The materials used in this study are; air dried leaves of Phyllanthus amarus, ethanol, glucose, test tube, yeast cell, hot air oven, centrifuge, distilled water, UV Spectrophotometer, beaker, water bath, electronic grinder, etc.

\section{Methods \\ Collection and identification of plant}

Fresh leaves of Phyllanthus amarus were collected in the evening hours from Bali Local Government Area of Taraba State and were identified by a Biologist, Mr. Ukwubile Cletus A. of the Department of Science Laboratory Technology, and a plant press was made and was deposited in the herbarium of Biology unit of Science Laboratory Technology Department Federal Polytechnic Bali, Taraba State with a voucher number PHY001.

\section{Preparation of plant extract for bioassay}

The leaves of the plant were shade dried on the laboratory table for 6 days and reduced to powder using grinder. This powder $(100 \mathrm{~g})$ was then packed into Soxhlet apparatus and extracted using $95 \%$ ethanol $\left(40-50^{\circ} \mathrm{C}\right)$. The extraction was carried out for $40 \mathrm{hrs}$. The yield obtained was $4.5 \%$ and the semi-solid extract was stored in a refrigerator at $4^{\circ} \mathrm{C}$ until further use.

\section{The antibacterial screening of plant extract against selected bacteria}

The method described by Kirby Bauer et al. 1996 was used. Briefly, extract concentration of $20 \mathrm{mg} / \mathrm{mL}$ was used as the initially, while agar made from blood was the growth medium. Exactly $40 \mathrm{~g}$ of the medium was dissolved in 1Litre distilled water in a flask covered with cotton wool. The medium was boiled on a Bunsen burner to dissolve. The content was sterilized at $121^{\circ} \mathrm{C}$ for $15 \mathrm{~min}$ before cooling. Twenty millimetre of the sterilized medium was then poured into sterile Petri dishes before allowing solidifying. The culturing plates were then inoculated with the test bacteria using spread plate technique, and allowed to dry for 1 hour. Using a sterilized cork borer which is $5 \mathrm{~mm}$ in diameter, various wells were made at the centre of each culturing plates and inoculated with the bacteria. Few volume of the plant extract was poured into the each wells using sterile $10 \mathrm{~mL}$ syringe. The culturing plates were then kept in a refrigerator at $37^{\circ} \mathrm{C}$ for $24 \mathrm{~h}$. The culturing plates then were observed for diameter zones of inhibition around the wells. These zones were determined using a transparent ruler and the values expressed in $\mathrm{mm}$ after three consecutive readings. ${ }^{10-15}$ Ciprofloxacin tablet $500 \mathrm{mg}$ was used as the positive control antibiotic due to its broad spectrum, while erythromycin tablet $500 \mathrm{mg}$ was used the negative control drug because of its narrow spectrum and these antibiotics were also inoculated the same way as the extract and bacteria.

\section{Determination of minimum inhibitory concentration (MIC) of plant extract against selected bacteria}

The minimum inhibitory concentration was carried out on those bacteria which displayed susceptibility towards the plant extract. This was carried out by broth dilution techniques. The aim was to find out the lowest concentration of plant extract which will retard the growth of these susceptible bacteria. Briefly, nutrient broth was prepared in accordance to the manufacturer's instructions contained on the label. Nutrient broth ions were disposed into five serial dilution test tubes for each bacterium. The tubes were then sterilized at $121{ }^{\circ} \mathrm{C}$ for $15 \mathrm{~min}$ in an autoclave to maintain $100 \%$ aseptic condition for microbial experiment. A Mc-Farland turbidity scale of number 0.5 was also prepared to determine turbidity of the bacterial suspensions. $10 \%$ normal saline was also prepared to ensure maximum asepticity of the media. After these, the bacteria were then inoculated into the normal saline until the turbidity became the same to that of the McFarland scale using visual sighting and this point of coincidence was noted and recorded as $1.5 \times 10^{8} \mathrm{cfa} / \mathrm{mL}$ which was the serial dilution factor. Serial dilution of plant extracts in the nutrient broth was carried out for each bacterium to get a concentration solutions of 20, 10, 5, 2.5 and $1.25 \mu \mathrm{g} / \mathrm{mL}$. A sterile pipette of $20 \mathrm{~mL}$ volume was then used to pipette $0.5 \mathrm{~mL}$ of the bacteria suspension into each serially diluted test tube, and then tubes were incubated at $37^{\circ} \mathrm{C}$ for $24 \mathrm{~h}$. Finally, the tubes were then observed for the presence of turbidity or growth of the media. The test tubes with the least concentration of plant extract with a clear solution that is no turbidity was taken as the MIC..$^{15}$

\section{The determination of minimum bactericidal concentration (MBC) of plant extract}

The minimum bactericidal concentration of the extract was determined in order to find out whether the bacteria were killed by the extract or only their growths were retarded. In this method, agar made from blood was prepared in accordance to the manufacturer's instructions as contained in the label, and sterilized at $121^{\circ} \mathrm{C}$ for 15 min in an autoclave. The content was then poured into sterilized Petri dishes before allowing them to solidify. These culturing plates were labelled accordingly to match with the MIC test tubes of each bacterium. After this step, MIC contents from the proceeding culturing test tubes in the serial dilution were then subculture into various plates by dipping a sterile wire loop and streaking the surface of the agar avoiding any form of contamination of the plates. The culturing plates were then incubated at $37^{\circ} \mathrm{C}$ for $24 \mathrm{~h}$ and then checked for growth of the media. Culturing plates having the lowest concentration of plant extract without any bacterial growth were taken as the MBC. ${ }^{15}$

\section{In vitro evaluation of yeast cell uptake of glucose}

Commercial baker's yeast was wash by repeated centrifugation $(3,000 \times \mathrm{g}, 5 \mathrm{~min})$ in distilled water until the supernatant fluid were 
clear and a $10 \%(\mathrm{v} / \mathrm{v})$ suspension was prepared in distilled various concentration of extracts $(1-5 \mathrm{mg} / \mathrm{mM})$ were added to $1 \mathrm{~mL}$ of glucose solution $(5,10$ and $25 \mathrm{mM})$ and further incubated for $10 \mathrm{~min}$ at $37^{\circ} \mathrm{C}$. reaction was started by adding $100 \mu 1$ of yeast suspension, vortex and further at $37^{\circ} \mathrm{C}$ at $60 \mathrm{~min}$, the tubes were centrifuged $(2,500 \times \mathrm{g}, 5 \mathrm{~min})$ and glucose was estimated in the supernatant, ${ }^{16-17}$ metformin was taken as standard anti-diabetic drug used. The percentage of increase in glucose uptake by yeast cells was calculated using the following formula:

$$
\text { Activity } \%=\frac{[(\text { Abscontrol }- \text { Abs sample }) / \text { Abs control }]}{(\text { Increase in } \text { glu cos euptake })} \times 100
$$

Where, Abs control is the absorbance of the control reaction (containing all reagents except the test sample) and Abs sample is the absorbance of the test sample. Absorbance was measured at $540 \mathrm{~nm}$ and all experiments were carried out in triplicates.

\section{Statistical analysis}

Values were recorded as mean \pm standard error of the mean Statistical difference between the means was determined by one-way ANOVA followed by Duncan multiple range test.

\section{Results and discussion}

In our study, both Gram-positive and Gram-negative bacterial growth were inhibited by $P$. amarus leaf ethanol extract although a greater susceptibility of Gram-positive bacteria was recorded. Among the bacteria tested, Salmonella typhi ATCC23564 was inhibited the most by the extract. This showed that $P$. amarus can be used to manage or treat infections caused by this organism. Susceptibility differences between Gram-positive and Gram-negative bacteria may be due to cell wall structural differences between these classes of bacteria. ${ }^{18}$ The fact that these microorganisms were susceptible to the extract is an indication that the plant is an excellent antibacterial agent in traditional medicine (Table 1). Many bacteria are very sensitive to flavonoid environments because their cell covering are denatured by the hydroxide group in the flavonoids making the bacteria prone to antibiotic attacks. The plant extract might have exhibited its bactericidal action against these microbes especially the Gram positive strain in this manner. Many classes of flavonoids have shown their ability to act on bacterial peptidoglycan causing irreversible reaction which favours drug penetration, and this was seen in the MBC results obtained from this study. It can then be said that $P$. amurus possessed antibacterial activity which are both bacteriostatic and bactericidal in action and justify its largely use as an ethnomedicinal plant in treating bacterial infections such as typhoid fever, staphylococcal, gonorrhoea, and spasm in children. The rate of glucose transport across cell membrane in yeast cells system is presented in Table 2. After treatment of yeast cells with the ethanol extract of $P$. amarus, no dose dependent glucose uptake was observed. The percentage of glucose uptake by yeast cells increase with glucose concentrations $(86-150 \mathrm{~nm})$ in the present of $100 \mu \mathrm{g} / \mathrm{mL}$ and $500 \mu \mathrm{g} /$ $\mathrm{mL}$ of $P$. amarus ethanol extract (PAEE), while it is not enhanced at 200,300 and $400 \mu \mathrm{g} / \mathrm{mL}$ of PAEE, except that $60.0 \%$ glucose uptake was in the present of $25 \mathrm{mM}$ glucose (Table 2).

The highest concentration of PAEE sample $(500 \mu \mathrm{g} / \mathrm{L}$ PAEE) exhibited maximum activity at all glucose concentrations (\% IC50) and showed the maximum increase of $(60.0 \%)$ in the present of at $25 \mathrm{mM}$ glucose. The mechanism of glucose transport across the yeast cell membrane has been receiving attention from in vitro screening method for hypoglycaemic effect of various compound/ medicinal plants. ${ }^{17}$ The result of the present study revealed that PAEE increased glucose uptake by yeast cells $(0-60 \%)$ at various glucose concentrations. The amount of glucose remaining in the medium after a specific time serve as an indicator of glucose uptake by yeast cells. ${ }^{18}$ Recent studies on the transport of non metabolizable sugars and glycosides suggest that sugar transport across the yeast cell membrane is mediated by stereo-specific membrane carrier. It is reported that in yeast cells (Saccharomyces cerevisiae) glucose transport is extremely complex, and it is generally agreed that glucose is transported in yeast by a facilitated diffusion process. This mechanism is the same from the results obtained in this study where there are dose-dependent IC50 (Table 2). Facilitated carriers are specific carriers that are capable of transporting solute down the concentration gradient, highlighting that the effect transport is only attained if there is removal of intracellular glucose. ${ }^{19}$ Hence, glucose transport occurs only if the intracellular glucose is effectively reduced (utilized). The present data, suggest that the plant extract is capable of enhancing glucose uptake effectively, which in turn suggest that it is capable of enhancing effective utilization at $500 \mu \mathrm{g} / \mathrm{mL}$ concentration, thereby controlling blood glucose level as also suggested by other reports. It therefore, justifies the claim of its use as an antidiabetic drug in traditional medicine comparatively, in the present study; the increased ability of the sample to absorb glucose may also be attributed to the dietary fiber (insoluble and soluble fibers) present in the sample. The maintenance of plasma glucose concentration for a long term under a variety of dietary conditions is one of the most important and closely regulated processes observed in the mammalian species (Figure 1)..$^{20-21}$

Table I In vitro antidiabetic activity of $P$ amarus

\begin{tabular}{lll}
\hline $\begin{array}{l}\text { No of test } \\
\text { tube }\end{array}$ & $\begin{array}{l}\text { Conc. of plant } \\
\text { exraxt }(\mu \mathrm{g} / \mathrm{mL})\end{array}$ & Abs $(\mathrm{nm})$ \\
\hline 0 & 100 & 105 \\
1 & 200 & 150 \\
2 & 300 & 110 \\
3 & 400 & 96 \\
4 & 500 & 86 \\
\hline
\end{tabular}

Table 2 Diameter zone of inhibition of the bacterial strains

\begin{tabular}{llll}
\hline & \multicolumn{2}{c}{$\begin{array}{l}\text { Diameter zone of } \\
\text { inhibition(mm) }\end{array}$} \\
\cline { 2 - 4 } Bacterial strain & Extract & $\begin{array}{l}\text { Positive } \\
\text { control }\end{array}$ & $\begin{array}{l}\text { Negative } \\
\text { control }\end{array}$ \\
\hline Bacillus subtilis ATCCI2432 & 25.25 & $24^{*}$ & 0 \\
Streptococcus pyogenes ATCC8668 & 23.5 & 15 & 0 \\
Staphylococcus aureusATCC29213 & $26.5 *$ & 14.5 & 0 \\
Salmonella typhi ATCC23564 & 40.5 & 19 & 0 \\
K. pneumonia (clinical isolate) & 22 & 19 & 0 \\
VRE ATCC6I23 & 25.12 & 22.51 & 0 \\
Campylobacter jejuni ATCCI33I5 & 32.21 & 0 & 0 \\
$\begin{array}{l}\text { Pseudomonas aeruginosa } \\
\text { ATCC8739I }\end{array}$ & 0 & 0 & 0 \\
\hline
\end{tabular}



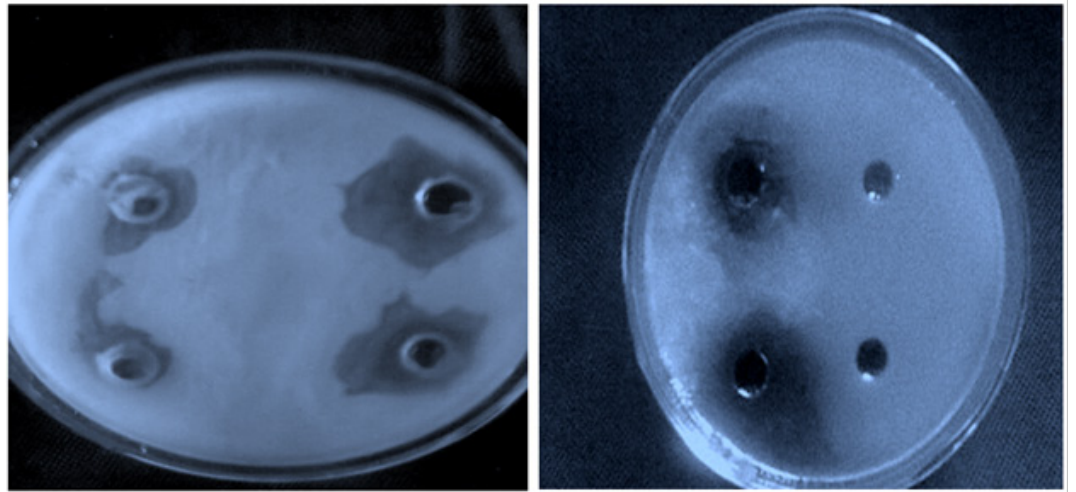

Figure I Diameter zone of inhibition of Salmonella typhi ATCC23564 against the positive control plate.

Note: Most of the bacteria showed MIC at $2.5 \mathrm{mg} / \mathrm{mL}$ and $\mathrm{MBC}$ at 5.0 and $10 \mathrm{mg} / \mathrm{mL}$ of the extract. At these concentrations, the bacteria were either inhibited in their growth or killed i.e. bactericidal.

\section{Conclusion}

The broad spectrum of bacterial susceptibilities indicate the potential of Phyllanthus amarus leaf ethanol extract as a surface disinfectant as well as for medicinal purposes especially in the treatment of typhoid fever, and possibly as food additives to inhibit bacterial growth in order to prevent food spoilage. However, further studies are required to ascertain its safety before use as food additive. Our study further revealed that the increase of glucose transport across cell membrane might be the anti-hyperglycemic mechanism of action of $P$. amarus leaf extract. The plant extract can therefore serve as a therapeutic agent and be used as a potential source of novel bioactive compounds for the treatment of typhoid fever, bacterial infections and Type II diabetes mellitus.

\section{Acknowledgements}

The authors are grateful to Mr Mika Nurah, Mr Abdulrazaq Babayo and Mr Livinus Tam, who helped us during this study.

\section{Conflict of interest}

Author declares that there is no conflict of interest.

\section{References}

1. Abirami N, Natarajan B. Isolation and characterization of $(4 z, 12 z)$ cyclopentaca-4 12 dienone from Indian Medicinal plant Grewia hirsute and its hyperglycaemic effect on 3 T3 and L6 cell lines. International Journal Pharm Boil Sci. 2014;6(2):393-398.

2. Anbu N, Musthafa M, Velpandian V. Antidiabetic activity of polyherbal formulation Aavarai yathichurnam in alloxan induced diabetic rats. $J$ Tradit Complement Med. 2012;4(2):77-80.

3. Ahmed F, Urooj A. In Vitro studies on the hypoglycaemic potential of Ficus racemosa Stem bark. J Sci Food Agric. 2010;90(3):397-401.

4. Cirillo VP. Mechanism of glucose transport across the yeast cell membrane. Journal of Bacteriology. 1962;84:485-491.

5. Sajeeth PK, Manna R. Antibacterial activity of some medicinal plants. Der Pharmacia Sinica. 2011;2 (2):220-226.
6. JMycek S. Harvey PC. Chape, Insulin and oral hypoglycaemic drugs in Lippincott`s illustrated Reviews. Pharmacology $2^{\text {nd }}$ ed. Lipincott William and Wilkins; USA. 2000.

7. Kerekou A, Zoumenous E, Agbantey M, et al. Study of the management of diabetic metabolic emergency in National teaching Hospital HKM of Cotonou. Journal of diabetes mellitus. 2014;4(4):359-370.

8. Cock IE. Antibacterial Activity of Selected Australian Native Plant Extracts. Internet Journal of Microbiology. 2008;4(2).

9. Marier A, Volker B, Boles E, et al. Characterization of glucose transport in Saccharomyces cerevisiae with plasma membrane vesicle (counter transport)and intact cells (initial uptake) with single Hxt1, Hxt2, Hxt3, Hxt4, Hxt5,Hxt6, Hxt7 or Gal2 transporters. FEMS Yeast Res. 2002;2(4):539-550.

10. Ojalla T, Remes S, Hams P. Antimicrobial activity of some coumarin containing herbal plants growing in finland. $J$ Ethnopharmacol. 1999;68(1-3):267-274.

11. Weksler Zangen S, Mizrahi T, Raz I, et al. Glucose tolerance factor extracted from yeast cell: oral insulin-mimetic and insulin-potentiating agent: in vivo and in vitro studies. Br J Nutr. 2012;108(5):875-882.

12. Kudi AC, Uhoh JU, Eduvie LO, et al. Screening of some Nigerian medicinal plants for antibacterial activity. Journal of Ethno-pharmacology. 1999;67: 225-228.

13. Veermuthu D, Muniappan A, Savarimuthu I. Antimicrobial activity of some ethnomedicinal plants used by paliyar tribe from Tamilnadu,India. BMC Complemetary \& Alternate Medicine. 2008;(35):231-236.

14. Ressel AD, Furr JR. Antibacterial activity of new chloroxenol preparation containing ethylene diamine tetracetic acid. $J$ Appl Bacterial. 1977;43(2):253-260.

15. Bauer AW, Kirby WM, Sherris JC, et al. Antibiotic susceptibility testing by a standardized single disk method. American Journal of Clinical Pathology, 1966;45(4):493-496.

16. Mbata TI, Saika A. Antibacterial activity and phytochemical screening of crude ethanolic extract of leaves of Ocimum gratissimum L. on Listeria monocytogenes. Internet journal of microbiology. 2008;4(2).

17. Meenaa V, Gandhiraja N, Sriram S, et al. Phytochemical screening and antimicrobial activity of the plant extracts of Mimosa pudica L. against selected microbes. Ethnobotanical leaflets. 2009;13(5):618-624. 
18. Khatune NA, Modsnaddik MA, Haque ME. Antibacterial activity and cytotoxicity of Nyctanthes arbar tristis flowers. Fitoterapia 2001;72(4):412-414.

19. Fine-Gold, Y.K. Antimicrobial Properties and Testing of Some West Africa Medicinal Plants II, Lind Schnelecter Quart. J. crude drug Res. 1990;170:78-80.
20. Facey PC,Pascoe KO, Porter RB, et al. Investigation of Plant used in Jamaican folk medicine for antibacterial activity. J. Pharm. Pharmacol. 1999;51(2):1455-1460.

21. Pitchaipillai R, Ponniah T. In Vitro Antidiabetic activity of ethanolic leaf extract of bruguiera cylindrica 1 . - glucose uptake by yeast cells method. Int Biol Biomed J Autumn. 2016;2(4):175-177. 